\title{
Urbanization, ethnicity and cardiovascular risk in a population in transition in Nakuru, Kenya: a population-based survey
}

\author{
Wanjiku Mathenge, Allen Foster, Hannah Kuper
}

\begin{abstract}
Background: Cardiovascular disease (CVD) is the leading cause of death among older people in Africa. This study aimed to investigate the relationship of urbanization and ethnicity with CVD risk markers in Kenya.

Methods: A cross-sectional population-based survey was carried out in Nakuru Kenya in 2007-2008. 100 clusters of 50 people aged $\geq 50$ years were selected by probability proportionate to size sampling. Households within clusters were selected through compact segment sampling. Participants were interviewed by nurses to collect sociodemographic and lifestyle information. Nurses measured blood pressure, height, weight and waist and hip circumference. A random finger-prick blood sample was taken to measure glucose and cholesterol levels. Hypertension was defined as systolic blood pressure (SBP) $\geq 140 \mathrm{~mm} \mathrm{Hg}$, or diastolic blood pressure (DBP) $\geq 90 \mathrm{~mm}$ $\mathrm{Hg}$ or current use of antihypertensive medication; Diabetes as reported current medication or diet control for diabetes or random blood glucose level $\geq 11.1 \mathrm{mmol} / \mathrm{L}$; High cholesterol as random blood cholesterol level $\geq 5.2$ $\mathrm{mmol} / \mathrm{L}$; and Obesity as Body Mass Index (BMI) $\geq 30 \mathrm{~kg} / \mathrm{m}^{2}$.

Results: 5010 eligible subjects were selected, of whom 4396 (88\%) were examined. There was a high prevalence of hypertension (50.1\%, 47.5-52.6\%), obesity (13.0\%, 11.7-14.5\%), diabetes (6.6\%, 5.6-7.7\%) and high cholesterol (21.1\%, 18.6-23.9). Hypertension, diabetes and obesity were more common in urban compared to rural groups and the elevated prevalence generally persisted after adjustment for socio-demographic, lifestyle, obesity and cardiovascular risk markers. There was also a higher prevalence of hypertension, obesity, diabetes and high cholesterol among Kikuyus compared to Kalenjins, even after multivariate adjustment. CVD risk markers were clustered both across the district and within individuals. Few people received treatment for hypertension (15\%), while the majority of cases with diabetes received treatment (68\%).
\end{abstract}

Conclusions: CVD risk markers are common in Kenya, particularly in urban areas. Exploring differences in CVD risk markers between ethnic groups may help to elucidate the epidemiology of these conditions.

\section{Background}

Infectious diseases are still the principal cause of death in Africa [1]. However, among older people coronary heart disease (CHD) and stroke are emerging as the leading cause, responsible for more than a quarter of deaths in people 60 years and over in Africa [2,3]. This represents a dramatic shift as CHD was virtually unknown in Africa until recently [4,5]. Stroke is particularly common in Africa in comparison to CHD [6], and

\footnotetext{
* Correspondence: hannah.kuper@lshtm.ac.uk
London School of Hygiene \& Tropical Medicine, Keppel Street, London

* Correspondence: hannah.kuper@lshtm.ac.uk
London School of Hygiene \& Tropical Medicine, Keppel Street, London WC1E 7HT, UK
} WCIE 71, UK

stroke mortality rates and prevalence of disabling stroke in most African countries are comparable to levels seen in high-income countries [7-9]. African countries are therefore experiencing a shift in the epidemiological transition [10], while retaining a high burden of infectious diseases.

The rise in cardiovascular disease (CVD) is linked to the increase in hypertension, diabetes, obesity, and high cholesterol observed in Africa in recent years. Obesity [11-14] and hypertension $[11,15-17]$ are now common throughout Africa, particularly in urban areas $[11,12,14,16,17]$. The number of people with diabetes in Sub-Saharan Africa is expected to more than double between 2000 and 2030 
[18], and diabetes is particularly common in urban areas [19]. Urbanisation is therefore a key feature in the rise of CVD. Currently $40 \%$ of Africans live in urban areas [20], and it is estimated that by 2030 half of Africans will live in urban areas. The Kenyan Luo Migration Study elegantly demonstrated the impact of rural-urban migration on CVD risk in Africa [21]. Rural migrants to Nairobi experienced a rise in systolic and diastolic blood pressure after only one month of migration. In contrast, the effect of rural-urban migration on blood pressure was not observed in a recent study in Tanzania, even though physical activity levels fell and weight increased after migration [22]. The discrepancy between the two studies may be because the rural-urban contrast in sodium intake was smaller in the Tanzanian compared to the Kenyan study (personal communication). The impact of ruralurban migration on health may therefore vary depending on setting.

People of African origin may be particularly vulnerable to hypertension. The prevalence of hypertension is high among people of African origin compared to Whites independent of BMI [23-25], and there is a younger age at onset in Africa [15] and among people of African descent [26]. Although the same risk markers are largely responsible for myocardial infarction (MI) across the globe [27], hypertension was associated with a higher MI risk in the Black African group than in the overall INTERHEART group [28]. There may also be greater difficulty in achieving control [26], and more aggressive presentation [26,29] and progress [28] of hypertension among people of African origin. This vulnerability may be due to lifestyle factors, but may also be influenced by ethnicity which varies widely within Africa and is linked to substantial heterogeneity in body composition [14], which may exert important metabolic effects [30].

The aim of this study was to investigate the relationship of urbanization and ethnicity with the prevalence of obesity, hypertension, diabetes and high cholesterol in a study of elderly people in Nakuru district, Kenya.

\section{Methods}

\section{Settings and population}

Nakuru district has a population of 1.2 million, one third of which is urban. Nakuru is broadly representative of Kenya in terms of ethnic diversity and economic activities. The two dominant ethnic groups are Kikuyus and Kalenjins. The Kikuyu are related to other Bantuspeaking peoples of East Africa while Kalenjins are of Nilotic origin.

During Jan 2007- Dec 2008, a sample of 100 clusters of 50 people aged $\geq 50$ years were selected across Nakuru district through probability proportionate to size sampling, using the electoral role as the sampling frame. Clusters were classed as "rural" or "urban" using the classification of the district statistical office. Households were selected within clusters through modified compact segment sampling [31]. The village leaders produced a sketch map of the polling area. The polling area was divided into segments each including approximately 50 people aged $\geq 50$ years. One segment was chosen at random by drawing lots and all households in the segment were included in the sample sequentially, until 50 people aged $\geq 50$ years were identified. If the segment did not include 50 people aged $\geq 50$ years then another segment was chosen at random and sampling continued.

The enumeration team visited households, assisted by a village guide, and invited all eligible participants aged $\geq 50$ years to the examination clinic which would be held at a convenient place in the cluster over the subsequent two days. Eligible participants were defined as those aged $\geq 50$ years resident in the cluster (i.e. living there at least 6 months per year) who had slept in the house either the night before or were planning on sleeping in the house that night. If an eligible person was absent then the survey team revisited the household at least two times.

\section{Examination clinic \\ Interviews}

Participants were interviewed by trained nurses. Information was collected on demographic data, education and assets (building materials of the house - type of walls, roof, floor and toilet; ownership of household assets - radio, TV, fridge, phone, cupboard, sofa set, sewing machine, table, bicycle and vehicle; animal ownership - cows, sheep/goats). People were asked whether their mother tongue was "Kikuyu", "Kalenjin" or other. For simplicity, people will be classified as "Kikuyu" and "Kalenjin" in the text. Information was also collected on health behaviour (smoking, alcohol use) and health status (diagnosis of diabetes or hypertension, family history and their treatment).

\section{Physical examination}

A nurse recorded the blood pressure of participants three times on the right arm of the participant, at least five minutes apart after an initial period of five minutes of rest using the Omron digital automatic monitor (model HEM907). A medium cuff size was used (to fit arms 22 to $32 \mathrm{~cm}$ ). The average of the last two readings was used as the measures of systolic and diastolic blood pressure (to nearest $1 \mathrm{~mm} \mathrm{Hg}$ ). A random finger-prick blood sample was taken to measure glucose (Accutrend GC system) and cholesterol levels (Accutrend GC system). The technical data from the company asserts that precision is $<3 \%$ for glucose and $<5 \%$ for cholesterol [32]. Weight was measured to the nearest $\mathrm{kg}$ using standard scales to the nearest $0.1 \mathrm{~kg}$ (Seca 761 scales) after the participant had removed all heavy clothing and 
shoes. Height was measured to the nearest $\mathrm{cm}$ while the participant stood without shoes using a standardized stadiometer (Leicester Height Measure). For weight and height the average of two readings was recorded. Waist and hip circumferences were measured with a tape. The waist circumference was measured at umbilicus level in mid-expiration to the nearest $0.1 \mathrm{~cm}$. The hip circumference was measured at the point of largest gluteal circumference to the nearest $0.1 \mathrm{~cm}$.

\section{Training}

The examination team received three weeks of training. Inter observer variation (IOV) was assessed during the training weeks at the Nakuru Provincial General Hospital. IOV on anthropometric variables were done by repeat measuring of 50 subjects by the two nurses. The level of agreement required was to the nearest $1 \mathrm{~cm}$ for circumferences and height, and to the nearest $0.5 \mathrm{~kg}$ for weight. The staff were retrained or replaced if IOV scores indicated poor comparability (kappa $<0.5$ ).

\section{Statistical analysis}

Statistical analyses were undertaken using the SAS statistical package (version 9.2). The four CVD risk markers considered were hypertension, diabetes, high cholesterol and obesity. Hypertension was defined as systolic blood pressure (SBP) was $\geq 140 \mathrm{~mm} \mathrm{Hg}$, or diastolic blood pressure (DBP) $\geq 90 \mathrm{~mm} \mathrm{Hg}$ or current use of antihypertensive medication [33]. Diabetes was defined as reported current medication (tablets or insulin) or diet control for diabetes or random blood glucose level $\geq 11.1 \mathrm{mmol} / \mathrm{L}$ [34]. People were categorized as having high cholesterol if their random blood cholesterol level was $\geq 5.2 \mathrm{mmol} / \mathrm{L}$ [35]. Obesity was defined as Body Mass Index $(B M I) \geq 30 \mathrm{~kg} / \mathrm{m}^{2}$ [36]. Prevalence estimates for the four CVD risk markers were calculated taking account of the design effect (DEFF) in estimating the confidence intervals. The DEFF was not taken into account for other analyses. A relative index of socioeconomic status (SES) was calculated based on building materials of the house, ownership of ten household assets and education status using principal components analysis [37]. The derived index was divided into quartiles from poorest to least poor.

We assessed the association between rural-urban status and, in turn, hypertension, diabetes, high cholesterol and obesity through logistic regression models. The models were adjusted in turn for, a) for age (50-59, 60$69,70-79, \geq 80$ ) and sex, b) age, sex and socio-demographic factors (SES score in quartiles), c) age, sex, BMI $(<20,20-25,>25-30, \geq 30)$, waist hip ratio (WHR - in quartiles), smoking (current, former, never) and alcohol (current, former, never), d) age, sex, diabetes and high cholesterol (as appropriate) and e) fully adjusted model.
These models were repeated assessing the association between the four CVD markers and Kikuyu or Kalenjin ethnicity, adjusting for urban status in models b and e. We included an interaction factor in the logistic regression models for ethnicity to assess whether there was an interaction between ethnicity and urban status in the relationship with CVD risk markers. We assessed the proportion of people receiving medical treatment among people who were defined as "hypertensive", and attempted to identify predictors of treatment status through logistic regression models. This was repeated for people with diabetes.

We assessed whether the CVD risk markers were clustered geographically by calculating the DEFF for each of the variables. We assessed whether there was clustering of the CVD risk markers within individuals. To do this, we derived expected frequencies of co-occurrence of risk markers (hypertension, diabetes, high cholesterol and obesity) from none through to four risk markers by combining probabilities, assuming a binomial distribution and independence between them [38]. We estimated observed to expected ratios for all participants and then separately for urban and rural groups and for Kikuyu and Kalenjin groups. We considered that there was clustering if the observed:expected ratios were high for no risk markers, low for one risk marker and high for three or more risk markers. We calculated chisquare statistics with 3 degrees of freedom to test the significance of the overall distribution of expected and observed counts within each group.

\section{Ethical approval}

Ethical approval for this work was granted by the London School of Hygiene \& Tropical Medicine and The Kenya Medical Research Institute Ethical Committee and Nakuru District Health Management Team. Informed consent was obtained from the subjects. All people with other treatable conditions were referred for appropriate treatment.

\section{Results}

We examined 4,396 (88\%) of the 5,010 people invited. Among those examined 1,437 (33\%) lived in urban and $2,959(67 \%)$ in rural areas (Table 1). Urban dwellers were younger, and had higher education levels and asset scores than rural dwellers. They were also more likely to be smokers and obese, than rural participants. Kikuyus made up $63 \%$ of the sample and Kalenjins $23 \%$ while the remaining $15 \%$ consisted of other language speakers. Kikuyus were more likely than Kalenjins to live in urban areas or to be female, and they had higher levels of education and higher SES scores. Kikuyus were less likely to be current smokers or consumers of alcohol. Kikuyus were significantly shorter yet heavier than Kalenjins 
Table 1 Demographic characteristics and health behavior comparing urban and rural participants, and Kikuyus and Kalenjins

\begin{tabular}{|c|c|c|c|c|c|c|}
\hline & $\begin{array}{l}\text { Urban } \\
(n=1437)\end{array}$ & $\begin{array}{l}\text { Rural } \\
(\mathrm{n}=2959)\end{array}$ & $\begin{array}{l}\text { Age and sex adjusted } \\
\text { OR }(95 \% \mathrm{Cl})\end{array}$ & $\begin{array}{l}\text { Kikuyu } \\
(\mathrm{n}=2760)\end{array}$ & $\begin{array}{l}\text { Kalenjin } \\
(\mathrm{n}=1015)\end{array}$ & $\begin{array}{l}\text { Age and sex adjusted } \\
\text { OR }(95 \% \mathrm{Cl})\end{array}$ \\
\hline \multicolumn{7}{|l|}{ Age } \\
\hline 50-59 & $57 \%$ & $38 \%$ & Baseline & $40 \%$ & $40 \%$ & Baseline \\
\hline $60-69$ & $26 \%$ & $31 \%$ & $0.6(0.5-0.7)$ & $32 \%$ & $28 \%$ & $1.2(1.0-1.4)$ \\
\hline 70-79 & $11 \%$ & $20 \%$ & $0.4(0.3-0.5)$ & $17 \%$ & $20 \%$ & $0.9(0.7-1.1)$ \\
\hline$\geq 80$ & $6 \%$ & $11 \%$ & $0.4(0.3-0.5)$ & $10 \%$ & $11 \%$ & $0.9(0.7-1.2)$ \\
\hline \multicolumn{7}{|l|}{ Sex } \\
\hline Men & $49 \%$ & $47 \%$ & Baseline & $44 \%$ & $53 \%$ & Baseline \\
\hline Women & $51 \%$ & $53 \%$ & $0.9(0.8-1.0)$ & $56 \%$ & $47 \%$ & $1.4(1.2-1.6)$ \\
\hline \multicolumn{7}{|l|}{ Language } \\
\hline Kikuyu & $65 \%$ & $62 \%$ & Baseline & & & \\
\hline Kalenjin & $6 \%$ & $31 \%$ & $0.2(0.1-0.2)$ & & & \\
\hline Other & $29 \%$ & $7 \%$ & $3.3(2.7-4.0)$ & & & \\
\hline Urban & & & & 931 (34\%) & $84(8 \%)$ & Baseline \\
\hline Rural & & & & 1812 (66\%) & 924 (92\%) & $5.7(4.5-7.2)$ \\
\hline \multicolumn{7}{|l|}{ Education } \\
\hline Any & $79 \%$ & $61 \%$ & $1.4(1.3-1.6)$ & $71 \%$ & $51 \%$ & $1.9(1.7-2.1)$ \\
\hline None & $21 \%$ & $39 \%$ & Baseline & $29 \%$ & $49 \%$ & Baseline \\
\hline \multicolumn{7}{|l|}{ SES score } \\
\hline 1 (poorest) & $8 \%$ & $33 \%$ & Baseline & $20 \%$ & $44 \%$ & Baseline \\
\hline 2 & $14 \%$ & $31 \%$ & $1.6(1.2-2.0)$ & $26 \%$ & $27 \%$ & $2.4(2.0-2.9)$ \\
\hline 3 & $24 \%$ & $26 \%$ & $3.1(2.5-3.9)$ & $27 \%$ & $20 \%$ & $3.4(2.8-4.2)$ \\
\hline 4 (richest) & $54 \%$ & $11 \%$ & $16.7(13.3-21.1)$ & $26 \%$ & $9 \%$ & $7.8(6.0-10.2)$ \\
\hline \multicolumn{7}{|l|}{ Smoking } \\
\hline Never & $70 \%$ & $70 \%$ & Baseline & $69 \%$ & $73 \%$ & Baseline \\
\hline Current & $7 \%$ & $8 \%$ & $1.4(1.1-1.8)$ & $8 \%$ & $6 \%$ & $0.5(0.3-0.6)$ \\
\hline Former & $23 \%$ & $22 \%$ & $1.1(0.9-1.3)$ & $24 \%$ & $20 \%$ & $2.0(1.6-2.5)$ \\
\hline \multicolumn{7}{|l|}{ Alcohol } \\
\hline Never & $41 \%$ & $38 \%$ & Baseline & $45 \%$ & $23 \%$ & Baseline \\
\hline Former & $41 \%$ & $46 \%$ & $0.9(0.7-1.0)$ & $44 \%$ & $49 \%$ & $0.4(0.3-0.5)$ \\
\hline Current & $18 \%$ & $17 \%$ & $0.9(0.7-1.1)$ & $11 \%$ & $28 \%$ & $0.2(0.1-0.2)$ \\
\hline \multicolumn{7}{|l|}{ BMl cat } \\
\hline Underweight & $8 \%$ & $17 \%$ & $0.7(0.5-0.9)$ & $12 \%$ & $21 \%$ & $0.7(0.6-0.9)$ \\
\hline Normal & $41 \%$ & $54 \%$ & Baseline & $48 \%$ & $56 \%$ & Baseline \\
\hline Overweight & $30 \%$ & $19 \%$ & $2.1(1.7-2.4)$ & $25 \%$ & $15 \%$ & $1.9(1.5-2.3)$ \\
\hline Obese & $20 \%$ & $10 \%$ & $2.8(2.3-3.5)$ & $14 \%$ & $8 \%$ & $2.0(1.5-2.6)$ \\
\hline
\end{tabular}

among both men $(166 \mathrm{~cm}$ vs $168 \mathrm{~cm}, 64 \mathrm{~kg}$ vs $60 \mathrm{~kg})$ and women $(156 \mathrm{~cm}$ vs $158 \mathrm{~cm}, 62 \mathrm{~kg}$ vs $58 \mathrm{~kg})$ and consequently had higher BMIs.

There was a high prevalence of hypertension $(50.1 \%$, $47.5-52.6 \%)$, obesity $(13.0 \%, 11.7-14.5 \%)$, diabetes $(6.6 \%$, 5.6-7.7\%) and high cholesterol (21.1\%, 18.6-23.9\%). Mean SBP and DBP were higher in urban than rural areas among both men and women (Table 2). Similarly, mean glucose and cholesterol levels and markers of obesity were higher in urban than rural men and this pattern was generally repeated among women. The prevalence of obesity generally fell sharply with age (Figure 1). The prevalence of hypertension increased steadily with age, and was consistently higher in urban than rural areas
(Figure 2). The association between prevalence and age were less clear for the diabetes (Figure 3) and high cholesterol (data not shown). Meanwhile, SBP increased with age while DBP decreased, and both remained higher for people from urban than rural areas across the age groups (Figure 4). Kikuyus had higher SBP than Kalenjins, but the differences were less clear for DBP (Table 3). Kikuyus also had higher levels of glucose, cholesterol, BMI and waist circumference but not of WHR. Kikuyus were more likely to be hypertensive, obese or diabetic in all age groups (Figure 5, 6, 7, 8).

The odds of hypertension was higher in urban than rural groups after adjustment for age and sex (Odds ratio $-\mathrm{OR}=1.7,95 \% \mathrm{CI}=1.5-1.9)($ Table 4$)$. The 
Table 2 Means (and standard error) of cardiovascular risk markers, by gender and urban-rural status

\begin{tabular}{lllllllll}
\hline & \multicolumn{3}{c}{} & \multicolumn{3}{c}{ Men } & \multicolumn{3}{c}{ Urban-rural comparison } & \multicolumn{2}{c}{ Women } \\
& No. Urban/Rural & Urban & Rural & Age adjusted p-value & No. Urban/Rural & Urban & Rural & Age adjusted p-value \\
\hline Mean SBP & $705 / 1395$ & $143(24)$ & $140(24)$ & $<0.0001$ & $726 / 1550$ & $143(26)$ & $140(25)$ & $<0.0001$ \\
Mean DBP & $705 / 1395$ & $84(14)$ & $81(13)$ & $<0.0001$ & $726 / 1550$ & $86(14)$ & $83(13)$ & $<0.0001$ \\
Glucose & $692 / 1373$ & $5.8(2.9)$ & $4.8(2.0)$ & $<0.0001$ & $704 / 1527$ & $5.7(2.8)$ & $5.1(2.3)$ & $<0.0001$ \\
Cholesterol & $698 / 1342$ & $4.5(0.9)$ & $4.3(0.9)$ & 0.0004 & $718 / 1514$ & $4.8(0.9)$ & $4.7(1.0)$ & 0.08 \\
BMI & $700 / 1385$ & $24(6)$ & $22(4)$ & $<0.0001$ & $718 / 1543$ & $27(6)$ & $24(6)$ & $<0.0001$ \\
Waist & $703 / 1390$ & $92(13)$ & $86(11)$ & $<0.0001$ & $719 / 1546$ & $96(13)$ & $89(13)$ & $<0.0001$ \\
WHR & $703 / 1390$ & $0.92(0.07)$ & $0.92(0.06)$ & 0.0009 & $718 / 1546$ & $0.89(0.06)$ & $0.89(0.08)$ & 0.34 \\
\hline
\end{tabular}

association was weakened after adjustment for SES markers and for obesity, smoking and alcohol, but not after adjustment for diabetes and cholesterol. In the fully adjusted model the odds of hypertension remained higher among urban compared to rural dwellers (1.3, 1.1-1.5). People in urban areas were also more likely to have diabetes $(2.3,1.8-2.9)$. The increased odds was reduced after adjustment for socio-demographic variables, though adjustment for other CVD risk markers had less effect. In the fully adjusted model the odds of diabetes was no longer elevated in urban compared to rural participants (1.3, 0.9-1.7). No clear association was apparent between the odds of high cholesterol and urban status. The pattern for the association between obesity and urban residence was similar to that for diabetes.

The odds of hypertension was higher among Kikuyus compared to Kalenjins (1.6, 1.4-1.8) (Table 5). The association persisted after adjustment for socio-demographic variables and other CVD risk markers (1.4, 1.2-1.7). Similarly, Kikuyus were more likely to have diabetes and high cholesterol, and these associations were not fully explained by adjustment for potential confounders. Kikuyus were more likely to be obese compared to Kalenjin, but not in models adjustment for SES and urban status. For all four risk markers, the biggest change in the association occurred after adjustment for SES and urban status.

There was no interaction between urban status and ethnicity for these conditions after adjustment for age and sex (data not shown).

There was substantial variation in the prevalence of hypertension (range 17-77\% (DEFF $=2.9$ ) diabetes (range $=0-26 \%$; DEFF $=1.8)$, high cholesterol (range $0-51.2 \%, \mathrm{DEFF}=4.3$ ) and obesity (range $0-40 \%, \mathrm{DEFF}=$ 1.8 ) between clusters. The variation was similar in rural and urban areas and among Kikuyus and Kalenjins.

Few people had 3-4 (4.5\%) or $2(18.5 \%)$ risk markers and the vast majority of the population had no (37.0\%) or one $(40.1 \%)$ risk marker (Table 6$)$. Generally rural dwellers and Kalenjins had fewer risk factors than urban dwellers and Kikuyus. There was a greater than expected

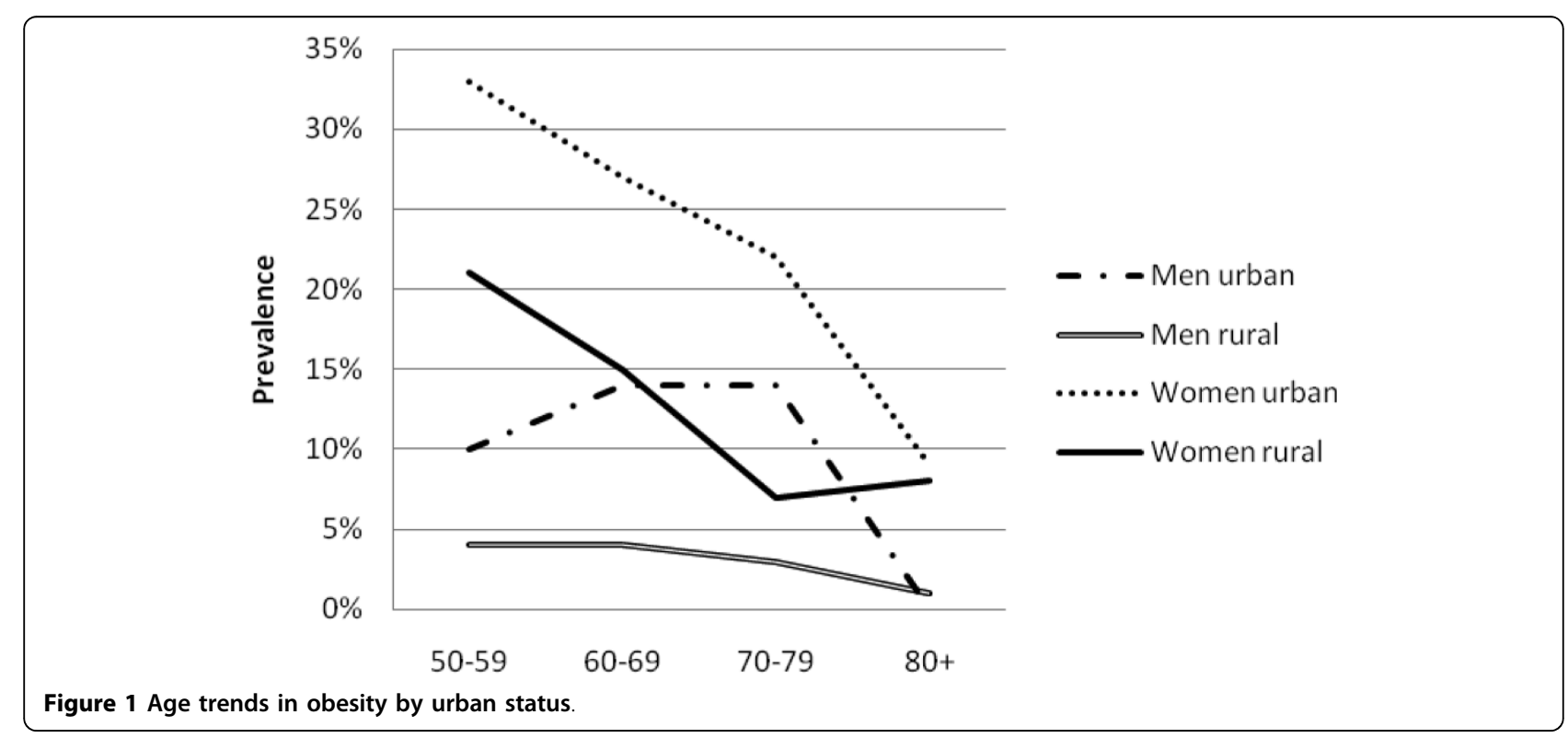




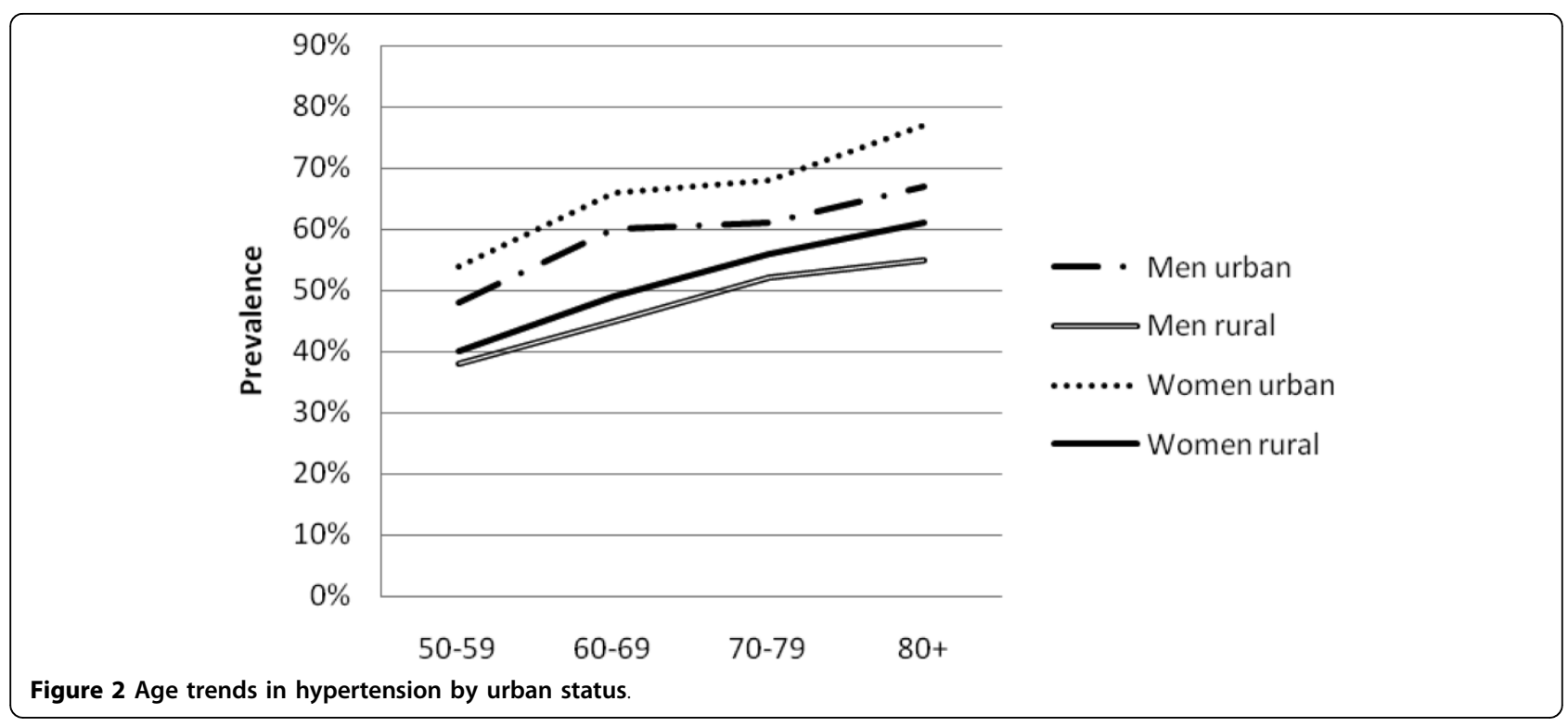

frequency of people with 3-4 risk markers than would be expected by chance, and to a lesser extent a higher frequency of people with no risk markers, except among Kalenijn. Together, this provides evidence for clustering of risk markers within individuals, which was more apparent among rural versus urban dwellers, and among Kalenjins compared to Kikuyus.

Among people with hypertension, only 323 (15\%) received drug treatment, 38 (2\%) received diet treatment and 7 traditional medicine treatment $(0.3 \%)$ (Table 7$)$. Among those on drug treatment, only 98 (29\%) had controlled hypertension. A far higher proportion of people with diabetes were receiving treatment (68\%), which included insulin $(\mathrm{n}=32)$, tablets $(\mathrm{n}=143)$ and/or diet control $(\mathrm{n}=43)$. A further 10 received traditional treatment. For both hypertension and diabetes, treatment was more among people living in urban areas, women, older people and those with a higher SES score. Kalenjins were less likely to receive treatment for hypertension than Kikuyus $(0.5,0.3-0.8)$, but there was no difference for diabetes.

\section{Sensitivity analysis}

We assessed the impact of lowering the threshold random blood glucose level for the classification of "diabetes". Lowering the threshold to $\geq 10 \mathrm{mmol} / \mathrm{L}$ added an additional 13 cases to the original 283 cases (revised prevalence $6.9 \%$ ), for $\geq 9 \mathrm{mmol} / \mathrm{L}$ this was 41 cases

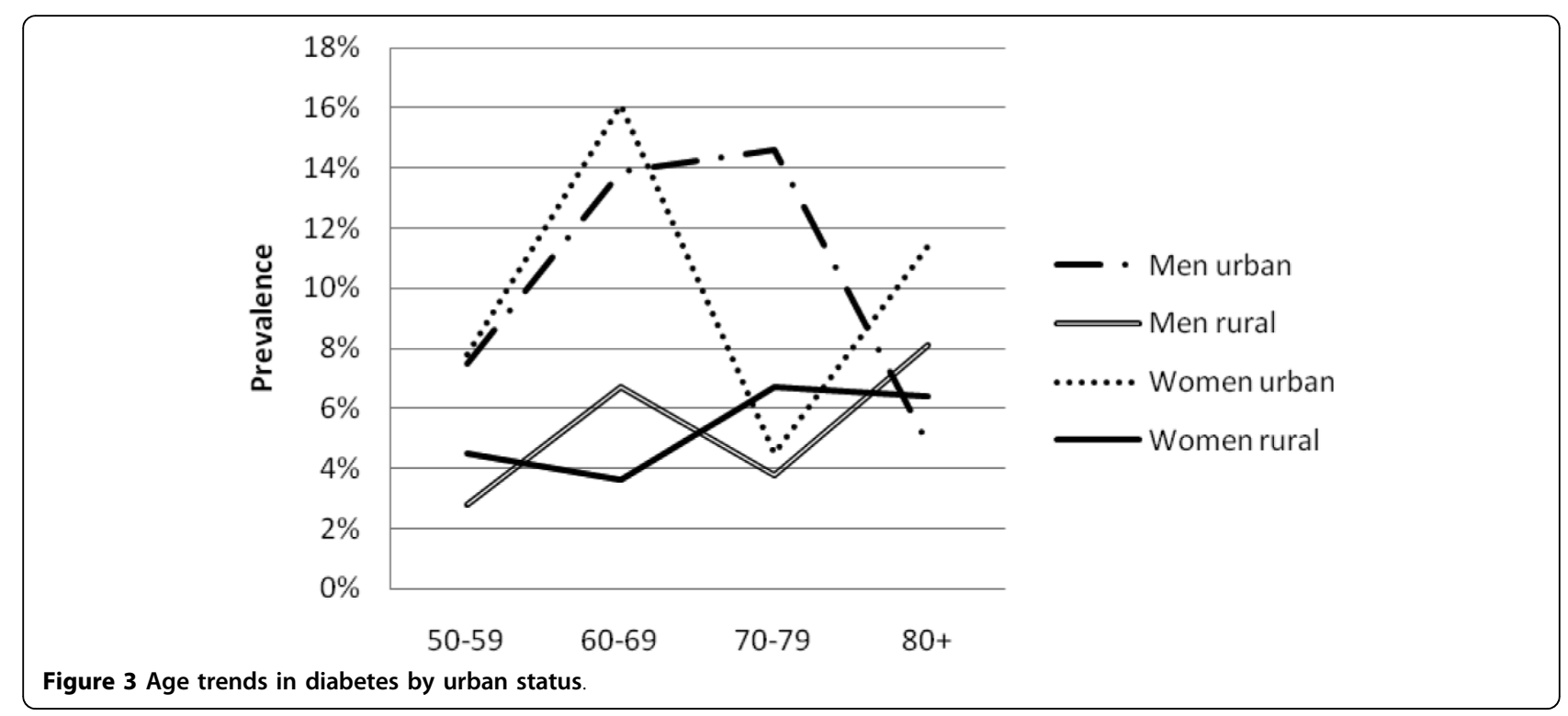




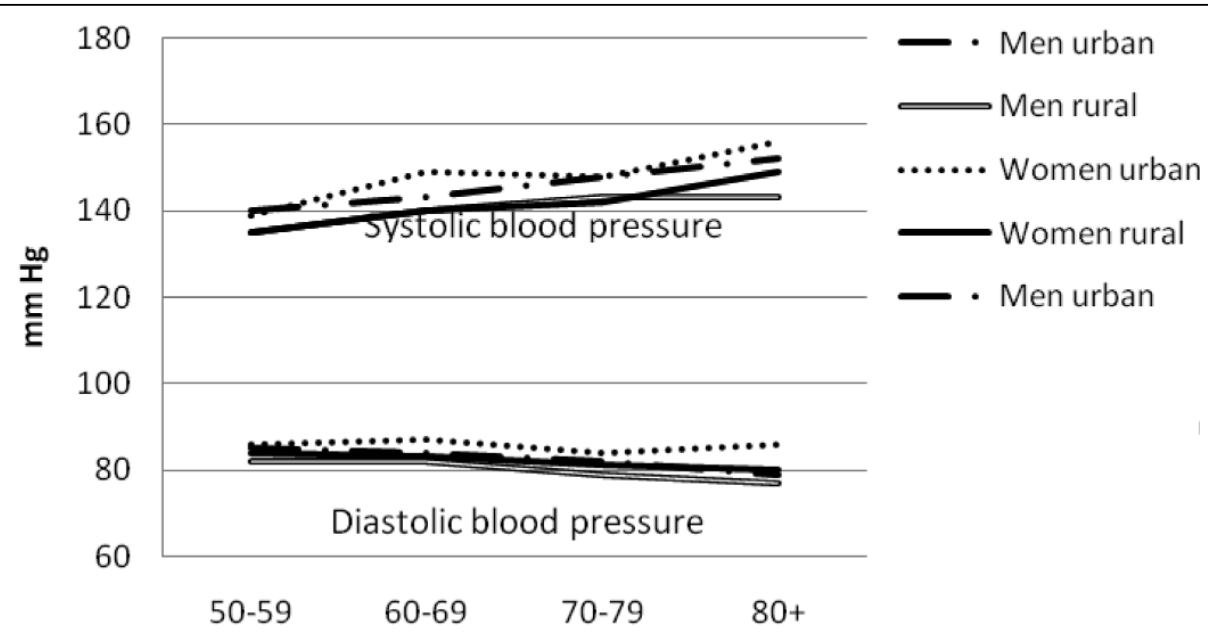

Figure 4 Age trends in systolic and diastolic blood pressure by urban status

Table 3 Means (and standard error) of cardiovascular risk markers, by gender and ethnicity

\begin{tabular}{|c|c|c|c|c|c|c|c|c|}
\hline & \multicolumn{8}{|c|}{ Kikuyu-Kalenjin comparison } \\
\hline & \multicolumn{4}{|c|}{ Men } & \multicolumn{4}{|c|}{ Women } \\
\hline & No. Kikuyu/Kalenjin & Kikuyu & Kalenjin & $\begin{array}{l}\text { Age adjusted } \\
\text { p-value }\end{array}$ & No. Kikuyu/Kalenjin & Kikuyu & Kalenjin & $\begin{array}{l}\text { Age adjusted } \\
\text { p-value }\end{array}$ \\
\hline Mean SBP & $1218 / 535$ & $142(24)$ & $139(23)$ & 0.007 & $1531 / 473$ & $142(26)$ & $136(24)$ & $<0.0001$ \\
\hline Mean DBP & $1218 / 535$ & $81(13)$ & $81(13)$ & 0.85 & $1531 / 473$ & $84(14)$ & $82(13)$ & 0.02 \\
\hline Glucose & $1209 / 515$ & $5.5(2.6)$ & $4.4(1.7)$ & $<0.0001$ & $1516 / 449$ & $5.5(2.6)$ & $4.9(2.0)$ & $<0.0001$ \\
\hline Cholesterol & $1177 / 524$ & $4.4(1.0)$ & $4.2(0.7)$ & $<0.0001$ & $1496 / 466$ & $4.8(1.0)$ & $4.5(1.0)$ & $<0.0001$ \\
\hline $\mathrm{BMI}$ & $1207 / 534$ & $23(5)$ & $21(4)$ & $<0.0001$ & $1519 / 469$ & $26(6)$ & $23(5)$ & $<0.0001$ \\
\hline Waist & $1213 / 535$ & $89(12)$ & $86(11)$ & 0.002 & $1522 / 470$ & $91(14)$ & $88(13)$ & $<0.0001$ \\
\hline WHR & $1213 / 535$ & $0.92(0.07)$ & $0.92(0.06)$ & 0.24 & $1521 / 470$ & $0.88(0.08)$ & $0.90(0.06)$ & $<0.0001$ \\
\hline
\end{tabular}

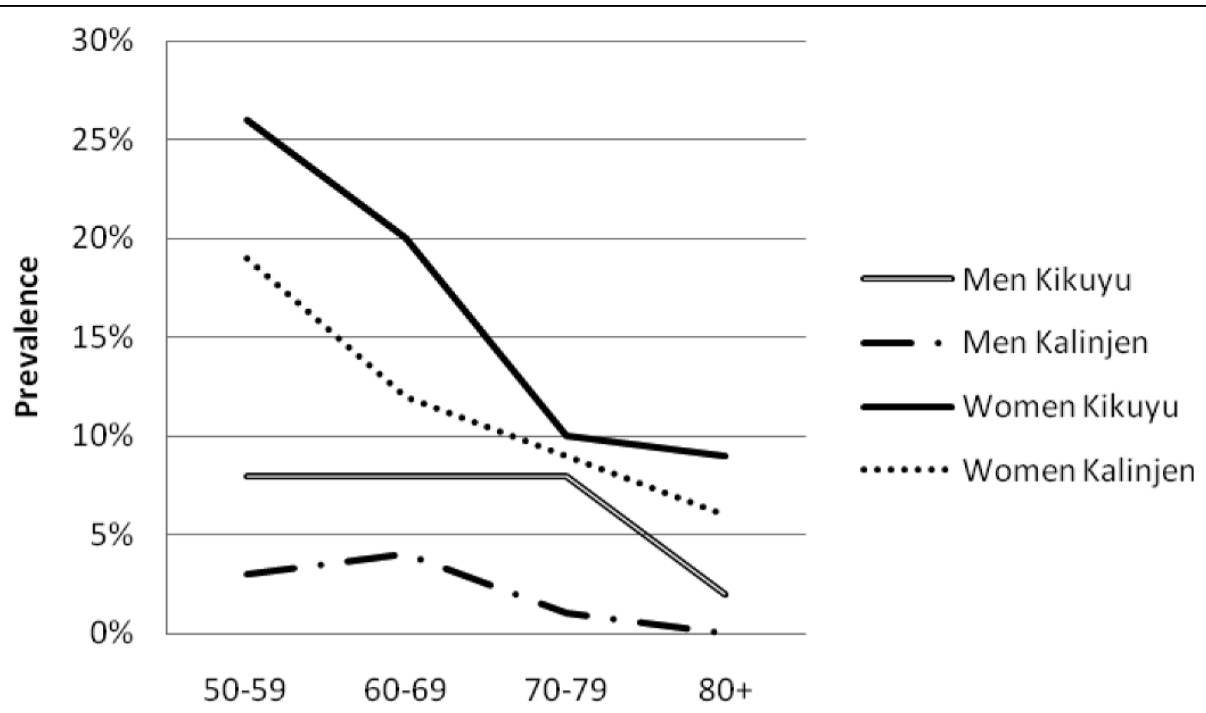

Figure 5 Age trends in obesity by ethnicity. 


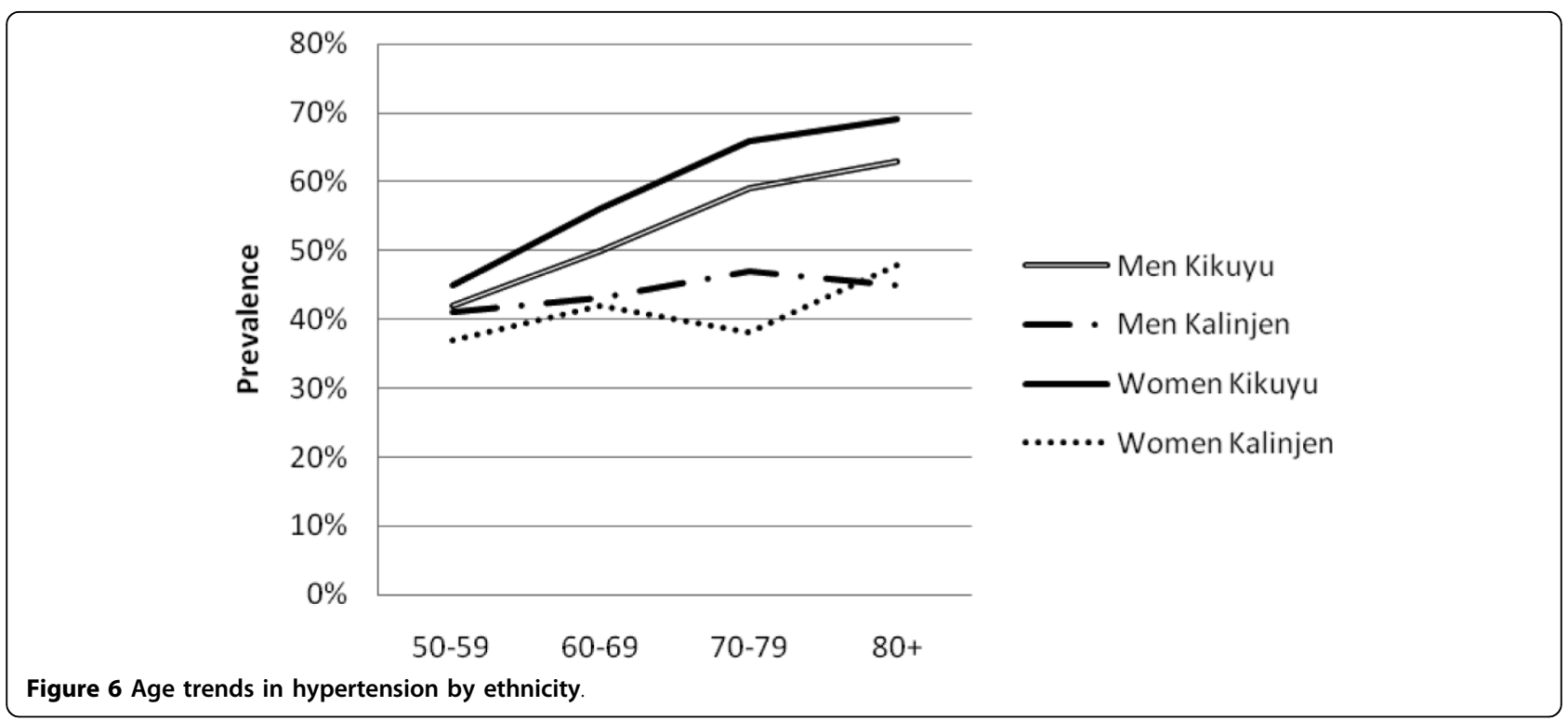

(7.5\%), for $\geq 8 \mathrm{mmol} / \mathrm{L}$ this was 84 cases $(8.5 \%)$ and for $\geq 7 \mathrm{mmol} / \mathrm{L}$ this was 180 cases $(10.8 \%)$. At the least conservative threshold for diabetes $(\geq 7 \mathrm{mmol} / \mathrm{L})$ almost half of cases $(42 \%)$ were receiving treatment.

\section{Discussion}

This large survey in Kenya highlighted the high prevalence of CVD risk markers, particularly in urban areas. SES was a more important mediator of the association between the individual CVD risk markers and urban status than health behavior or other CVD markers. However, the urban-rural differences in hypertension and obesity were not explained fully after adjustment for SES, obesity, smoking, alcohol or other CVD risk markers. The prevalence of CVD risk markers was higher among Kikuyus than among Kalenjins. Again, these associations were not fully explained after adjustment for the possible confounders, including urban status. A high degree of clustering of these risk markers was apparent, both geographically and within individuals. The clustering within individuals was more marked among rural dwellers and Kalenjins, although they had fewer people with risk factors overall, potentially indicating that there were a few early adopters of these multiple risk factors compared to the more well established presence among urban dwellers and Kikuyus. Only $15 \%$ of people with hypertensive were receiving treatment, and this was particularly low among poorer

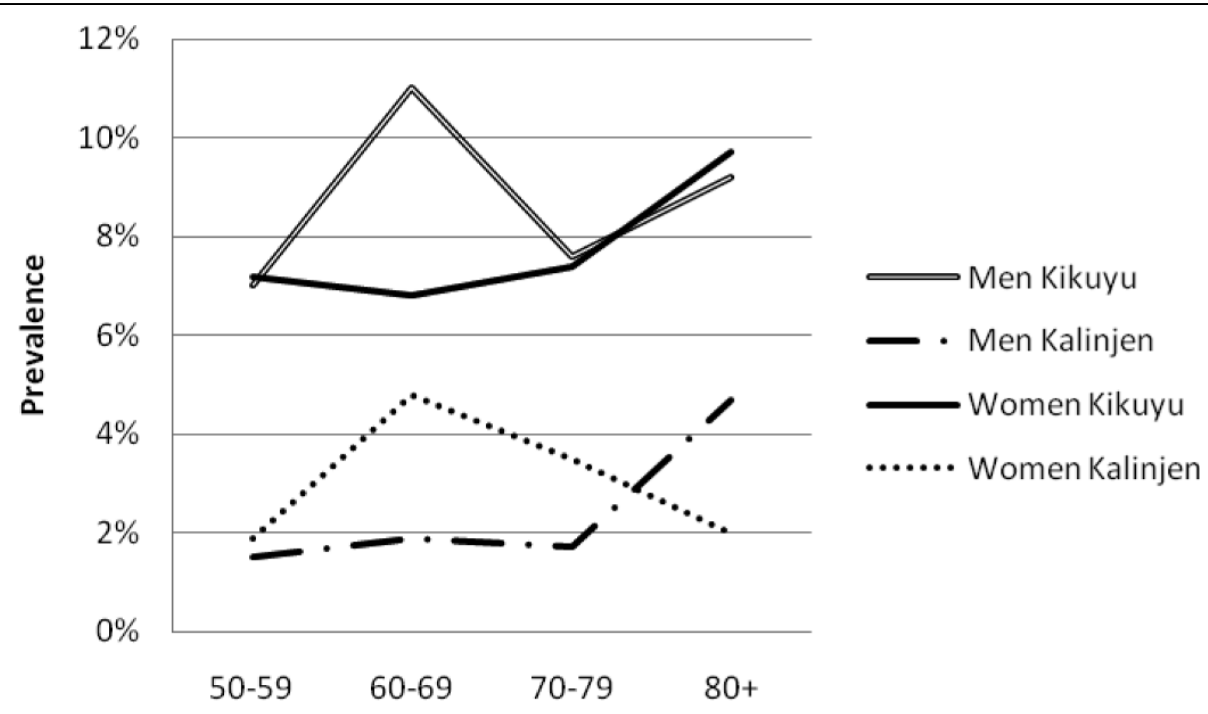

Figure 7 Age trends in diabetes by ethnicity. 


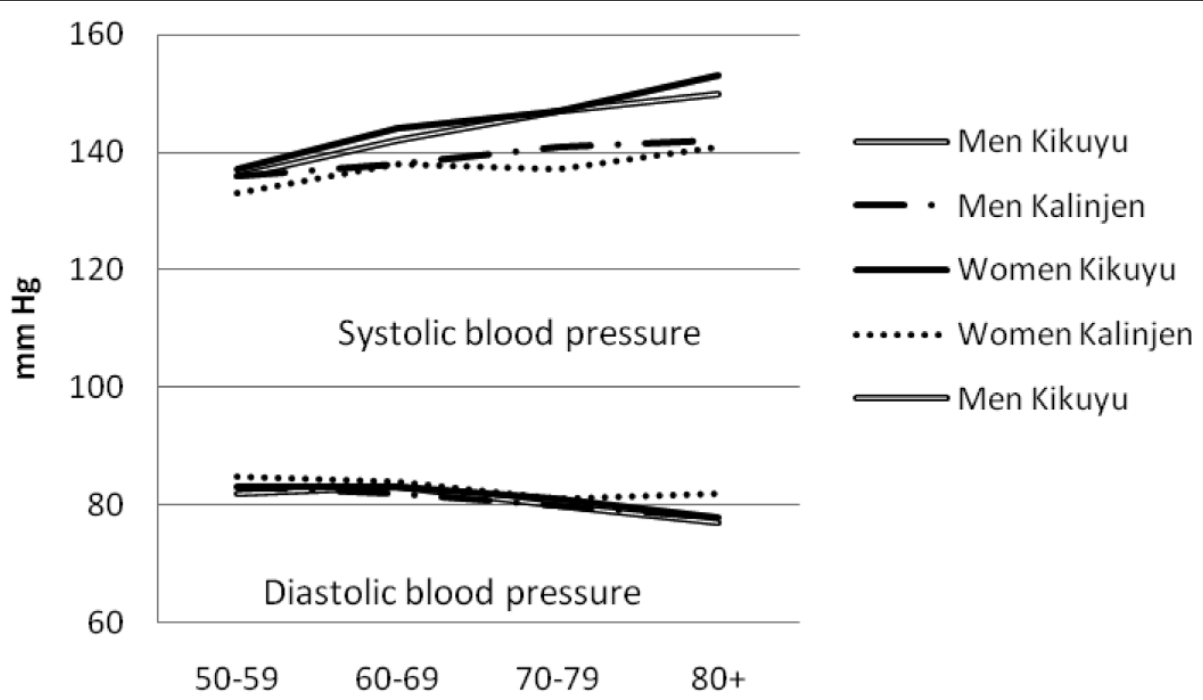

Figure 8 Age trends in systolic and diastolic blood pressure by ethnicity

Table 4 Rural-urban differences in the prevalence of CVD risk markers

\begin{tabular}{|c|c|c|c|c|c|c|c|}
\hline & $\begin{array}{l}\text { Urban } \\
(n=1431)\end{array}$ & $\begin{array}{l}\text { Rural } \\
(n=2945)\end{array}$ & $\begin{array}{l}\text { Age and sex } \\
\text { adjusted OR } \\
(95 \% \mathrm{Cl})\end{array}$ & $\begin{array}{l}\text { Age, sex and socio- } \\
\text { demographic adjusted } \\
\text { OR (SES score) }\end{array}$ & $\begin{array}{l}\text { Age, sex, BMI, } \\
\text { WHR, smoking, } \\
\text { alcohol }\end{array}$ & $\begin{array}{l}\text { Age, sex, } \\
\text { diabetes, } \\
\text { cholesterol, } \\
\text { hypertension }\end{array}$ & $\begin{array}{l}\text { Fully } \\
\text { adjusted } \\
\text { model }\end{array}$ \\
\hline Hypertension & 812 (57\%) & 1379 (47\%) & $1.7(1.5-1.9)$ & $1.4(1.2-1.6)$ & $1.4(1.2-1.6)$ & $1.6(1.4-1.8)$ & $1.3(1.1-1.5)$ \\
\hline Normotensive & $619(43 \%)$ & 1566 (53\%) & Baseline & Baseline & Baseline & Baseline & Baseline \\
\hline Diabetic & $139(10.0 \%)$ & $144(5.0 \%)$ & $2.3(1.8-2.9)$ & $1.3(1.0-1.7)$ & $2.0(1.5-2.5)$ & $2.2(1.7-2.8)$ & $1.3(0.9-1.7)$ \\
\hline Normal & $1256(90.0 \%)$ & 2756 (95.0\%) & Baseline & Baseline & Baseline & Baseline & Baseline \\
\hline $\begin{array}{l}\text { High } \\
\text { cholesterol }\end{array}$ & $316(22 \%)$ & $588(21 \%)$ & $1.2(1.0-1.4)$ & $0.9(0.8-1.1)$ & $1.0(0.9-1.2)$ & $1.1(0.9-1.3)$ & $0.9(0.7-1.1)$ \\
\hline $\begin{array}{l}\text { Normal } \\
\text { cholesterol }\end{array}$ & 1100 (78\%) & 2268 (79\%) & Baseline & Baseline & Baseline & Baseline & Baseline \\
\hline Obese & 287 (20\%) & $280(10 \%)$ & $2.3(1.9-2.8)$ & $1.3(1.0-1.6)$ & $2.9(2.3-3.5)$ & $2.2(1.8-2.7)$ & $1.5(1.2-1.9)$ \\
\hline Not obese & 1131 (80\%) & 2648 (90\%) & Baseline & Baseline & Baseline & Baseline & Baseline \\
\hline
\end{tabular}

Table 5 Kikuyu-Kalenjin differences in the prevalence of CVD risk markers

\begin{tabular}{|c|c|c|c|c|c|c|c|}
\hline & Kikuyus & Kalenjins & $\begin{array}{l}\text { Age and sex } \\
\text { adjusted OR } \\
(95 \% \mathrm{Cl})\end{array}$ & $\begin{array}{l}\text { Age, sex and socio- } \\
\text { demographic adjusted OR } \\
\text { (SES score and urban) }\end{array}$ & $\begin{array}{l}\text { Age, sex, BMI, } \\
\text { WHR, } \\
\text { smoking, } \\
\text { alcohol }\end{array}$ & $\begin{array}{l}\text { Age, sex, } \\
\text { diabetes, } \\
\text { cholesterol, } \\
\text { hypertension }\end{array}$ & $\begin{array}{l}\text { Fully } \\
\text { adjusted } \\
\text { model }\end{array}$ \\
\hline Hypertension & 1445 (53\%) & 420 (42\%) & $1.6(1.4-1.8)$ & $1.3(1.1-1.5)$ & $1.5(1.3-1.8)$ & $1.5(1.3-1.7)$ & $1.4(1.2-1.7)$ \\
\hline Normotensive & $1304(47 \%)$ & $588(58 \%)$ & Baseline & Baseline & Baseline & Baseline & Baseline \\
\hline Diabetic & $219(8 \%)$ & $24(2 \%)$ & $3.4(2.2-5.3)$ & $2.2(1.4-3.4)$ & $3.4(2.2-5.4)$ & $3.3(2.2-5.2)$ & $2.3(1.5-3.8)$ \\
\hline Normal & 2506 (92\%) & 940 (98\%) & Baseline & Baseline & Baseline & Baseline & Baseline \\
\hline $\begin{array}{l}\text { High } \\
\text { cholesterol }\end{array}$ & 648 (24\%) & $142(14 \%)$ & $1.8(1.5-2.2)$ & $1.6(1.3-2.0)$ & $1.6(1.3-2.0)$ & $1.7(1.4-2.1)$ & $1.5(1.2-1.9)$ \\
\hline $\begin{array}{l}\text { Normal } \\
\text { cholesterol }\end{array}$ & 2025 (76\%) & 848 (86\%) & Baseline & Baseline & Baseline & Baseline & Baseline \\
\hline Obese & 392 (14\%) & $80(8 \%)$ & $1.8(1.4-2.3)$ & $1.0(0.8-1.3)$ & $2.0(1.5-2.7)$ & $1.7(1.3-2.2)$ & $1.0(0.7-1.4)$ \\
\hline Not obese & $2334(86 \%)$ & $923(92 \%)$ & Baseline & Baseline & Baseline & Baseline & Baseline \\
\hline
\end{tabular}


Table 6 Clustering of risk markers by rural-urban status and ethnicity

\begin{tabular}{|c|c|c|c|c|c|c|c|c|c|c|c|c|c|c|c|}
\hline \multirow[t]{2}{*}{ No. of risk markers* } & \multicolumn{3}{|c|}{ Total group } & \multicolumn{3}{|l|}{ Urban } & \multicolumn{3}{|l|}{ Rural } & \multicolumn{3}{|l|}{ Kikuyu } & \multicolumn{3}{|c|}{ Kalenjin } \\
\hline & $\operatorname{Exp}^{* *}$ & Obs & O:E & $\operatorname{Exp}^{* *}$ & Obs & $\mathrm{O}: \mathrm{E}$ & $\operatorname{Exp}^{* *}$ & Obs & O:E & $\operatorname{Exp}^{* *}$ & Obs & $\mathrm{O}: \mathrm{E}$ & $\operatorname{Exp}^{* *}$ & Obs & O:E \\
\hline 0 & 32.0 & 37.0 & 116 & 24.1 & 30.0 & 124 & 36.3 & 40.4 & 111 & 28.3 & 33.1 & 117 & 44.8 & 47.0 & 105 \\
\hline 1 & 47.7 & 40.1 & 84 & 47.4 & 38.6 & 81 & 47.1 & 40.9 & 87 & 47.6 & 40.3 & 85 & 44.6 & 40.8 & 92 \\
\hline 2 & 17.9 & 18.5 & 103 & 23.8 & 24.9 & 104 & 15.0 & 15.3 & 102 & 20.8 & 21.3 & 102 & 9.9 & 10.7 & 108 \\
\hline $3-4$ & 2.3 & 4.5 & 193 & 4.4 & 6.5 & 148 & 1.5 & 3.5 & 228 & 3.2 & 5.2 & 165 & 0.7 & 1.6 & 233 \\
\hline$X^{2}(3 d f)$ & \multicolumn{3}{|c|}{$71.6 P<0.0001$} & \multicolumn{3}{|c|}{$27.0 p<0.0001$} & \multicolumn{3}{|c|}{$39.3 p<0.0001$} & \multicolumn{3}{|c|}{$40.3 p<0.0001$} & \multicolumn{3}{|c|}{$6.2 p=0.10$} \\
\hline
\end{tabular}

*Hypertension, obesity, diabetes and high cholesterol.

**Based on random assortment of four risk marker.

people or rural dwellers. In contrast, more than two thirds of people with diabetes were receiving treatment, although this proportion fell if a lower blood glucose threshold was used for diagnosis of diabetes.

The urban-rural differences in CVD risk markers are likely to be explained by differences in health behavior, including diet and physical activity. These urban-rural differences in lifestyle may in turn explain some of the differences in CVD risk markers between Kikuyus and Kalenjins. However, Kikuyu and Kalenjin participants clearly differed in physical characteristics, such as height, weight and waist and hip circumferences, and these may exert metabolic consequences [30], and explain some of the differences in CVD risk markers.

The prevalence of hypertension in men in our survey was generally high compared to other world regions, and exceeded the prevalence in the Established Market Economies and Latin American Countries for the oldest age group [15]. For women in our survey the pattern was more typical to that seen in the sub-Saharan Africa

Table 7 Treatment for hypertension and diabetes

\begin{tabular}{|c|c|c|c|c|c|c|c|c|}
\hline \multirow[b]{3}{*}{ Number } & \multicolumn{5}{|c|}{ Hypertension } & \multicolumn{3}{|c|}{ Diabetes } \\
\hline & $\begin{array}{l}\text { Drug } \\
\text { treatment } *\end{array}$ & $\begin{array}{l}\text { No } \\
\text { treatment }\end{array}$ & $\begin{array}{l}\% \\
\text { untreated }\end{array}$ & $\begin{array}{l}\text { Multivariate adjusted OR } \\
(95 \% \mathrm{Cl})^{* * *}\end{array}$ & Treatment ${ }^{* *}$ & $\begin{array}{l}\text { No } \\
\text { treatment }\end{array}$ & $\begin{array}{l}\% \\
\text { untreated }\end{array}$ & $\begin{array}{l}\text { Multivariate adjusted OR } \\
(95 \% \mathrm{Cl}) * * *\end{array}$ \\
\hline & 323 & 1868 & & & 196 & 91 & & \\
\hline Rural & 191 & 621 & $76 \%$ & Baseline & 86 & 59 & $41 \%$ & Baseline \\
\hline Urban & 132 & 1247 & $90 \%$ & $1.6(1.2-2.1)$ & 110 & 32 & $23 \%$ & $2.0(1.1-3.8)$ \\
\hline \multicolumn{9}{|c|}{ Language } \\
\hline Kikuyu & 232 & 1213 & $84 \%$ & Baseline & 152 & 69 & $31 \%$ & Baseline \\
\hline Kalenjin & 20 & 400 & $95 \%$ & $0.5(0.3-0.8)$ & 15 & 10 & $40 \%$ & $0.9(0.3-2.1)$ \\
\hline Other & 72 & 255 & $78 \%$ & $1.3(0.9-1.8)$ & 29 & 12 & $29 \%$ & $0.9(0.4-2.0)$ \\
\hline \multicolumn{9}{|l|}{ Age } \\
\hline $50-59$ & 128 & 726 & $85 \%$ & Baseline & 67 & 40 & $37 \%$ & Baseline \\
\hline $60-69$ & 107 & 561 & $84 \%$ & $1.7(1.2-2.3)$ & 74 & 29 & $28 \%$ & $1.9(1.0-3.5)$ \\
\hline 70-79 & 57 & 357 & $86 \%$ & $2.0(1.4-3.0)$ & 34 & 12 & $26 \%$ & $3.3(1.4-7.9)$ \\
\hline$\geq 80$ & 31 & 224 & $88 \%$ & $2.0(1.2-3.3)$ & 21 & 10 & $32 \%$ & $2.6(0.9-7.3)$ \\
\hline Male & 93 & 923 & $91 \%$ & Baseline & 92 & 47 & $34 \%$ & Baseline \\
\hline Female & 230 & 945 & $80 \%$ & $3.4(2.5-4.5)$ & 104 & 44 & $30 \%$ & $1.8(1.0-3.1)$ \\
\hline \multicolumn{9}{|l|}{ SES score } \\
\hline $\begin{array}{l}1 \\
\text { (poorest) }\end{array}$ & 23 & 456 & $95 \%$ & Baseline & 14 & 11 & $44 \%$ & Baseline \\
\hline 2 & 39 & 456 & $92 \%$ & $1.4(0.8-2.3)$ & 19 & 22 & $54 \%$ & $0.7(0.3-2.1)$ \\
\hline 3 & 87 & 493 & $85 \%$ & $2.7(1.7-4.4)$ & 60 & 24 & $29 \%$ & $2.3(0.9-5.9)$ \\
\hline 4 (richest) & 169 & 456 & $73 \%$ & $4.7(2.9-7.7)$ & 102 & 33 & $24 \%$ & $2.2(0.8-5.8)$ \\
\hline \multicolumn{9}{|c|}{ Schooling } \\
\hline Any & 249 & 1217 & $83 \%$ & $1.3(1.1-1.5)$ & 41 & 24 & $37 \%$ & $1.2(0.8-1.8)$ \\
\hline None & 74 & 651 & $90 \%$ & Baseline & 155 & 67 & $30 \%$ & Baseline \\
\hline
\end{tabular}

*Treatment for hypertension included drug treatment only.

**Treatment for diabetes included insulin, tablets or diet control.

*** Adjusted for age, sex, urban/rural, ethnic group, SES score, schooling. 
region. Other studies from Africa confirm the higher prevalence of hypertension, diabetes and obesity in urban compared to rural populations $[11,12,14,16,17,19,39]$. Previous surveys confirm our finding of a higher prevalence of obesity among women compared to men in Africa [12-14], and suggest that BMI differences between rural and urban areas drive differences in diabetes prevalence [39]. Few people with hypertension were currently treated in the Nakuru survey, which is consistent with the findings from other African settings [7,17,40], while the proportion of people with diabetics receiving treatment was higher than in other surveys [39].

The high prevalence of CVD markers in Nakuru, particularly hypertension, is likely to be of substantial public health importance, as untreated hypertension is an important modifiable risk factor for stroke in Africa $[7,41]$. This is compounded by the low proportion of hypertensives receiving treatment in this population, although the situation was better for diabetes. The rise of non communicable diseases are likely to put further pressure on an already overstretch primary health care system [9], and so prevention is important potentially through reducing obesity and salt intake $[23,42,43]$. Further studies investigating means of reducing hypertension in Africa are needed urgently [44].

There were a number of limitations to this study. The study design was a cross-sectional survey, and so we could not take account of the temporal relationship between potential risk markers and outcomes. We measured blood pressure on only one day and so regression to the mean was possible, and one cuff size was used for all participants. The blood glucose measures were obtained from non-fasting blood samples, rather than through use of the oral glucose tolerance test or fasting blood glucose, and this may have underestimated the prevalence of diabetes. Lowering the threshold blood glucose level cut-off for the definition of diabetes increased the prevalence, however, this was not substantial until the level was reduced to $>7 \mathrm{mmol} / \mathrm{L}$. We measured smoking and alcohol status, but we did not assess physical activity or diet or other blood markers (e.g. renin), which were potentially important explanatory variables. Although we measured BMI and WHR, it would have been useful to include bioimpedance as a measure of body fat. Classifying people as "Kikuyu" or "Kalenjin" on the basis of their mother tongue may have been over-simplistic. This study also had important strengths. There was a high response rate, and the sample was representative across Nakuru, limiting the impact of selection bias. We included a measure of SES which was previously validated for this area [37]. The measures of blood pressure and anthropometry were assessed by trained medical staff.

\section{Conclusions}

The burden of CVD risk markers is high in Kenya, particularly in urban areas. Exploring differences in CVD risk markers between ethnic groups may help us to elucidate the epidemiology of these conditions in Africa.

\section{Abbreviations}

BMI: Body Mass Index; CHD: Coronary heart disease (CHD); CVD: Cardiovascular disease; DBP: Diastolic blood pressure; DEFF: Design effect; IOV: Inter observer variation; MI: Myocardial infarction; SBP: Systolic blood pressure; SES: Socio-economic status; WHR: Waist hip ratio.

\section{Acknowledgements}

This study was funded by a grant from the British Council for Prevention of Blindness and through support from the Fred Hollows Foundation.

\section{Authors' contributions}

WM was responsible for carrying out the fieldwork and the cleaning and preparation of the database. HK and AF assisted with the design and supervision of the fieldwork. HK was primarily responsible for the data analysis and producing the first draft of the paper. All authors read and approved the final manuscript.

\section{Competing interests}

The authors declare that they have no competing interests.

Received: 17 May 2010 Accepted: 22 September 2010

Published: 22 September 2010

\section{References}

1. Lopez AD, Mathers CD, Ezzati M, Jamison DT, Murray CJ: Global and regional burden of disease and risk factors, 2001: systematic analysis of population health data. Lancet 2006, 367(9524):1747-1757.

2. Jamison DT, Feachem FG, Makgoba MW, Bos ER, Baingana FK, Hofman KJ, Rogo KO, (Eds.): Disease and Mortality in Sub-Saharan Africa Washington D. C.: World Bank 2006.

3. Mathers CD, Bernard C, Iburg K, Inoue M, Ma Fat D, Shibuya K, Stein C, Tomijima N: The Global Burden of Disease in 2002: data sources, methods and results.Edited by: World Health Organization. Geneva: World Health Organization; 2003:

4. Walker AR, Walker BF, Segal I: Some puzzling situations in the onset, occurrence and future of coronary heart disease in developed and developing populations, particularly such in sub-Saharan Africa. $J R$ Soc Promot Health 2004, 124(1):40-46.

5. Mensah GA: Ischaemic heart disease in Africa. Heart 2008, 94(7):836-843.

6. Rao C, Lopez AD, Hemed Y: Causes of Death. In Disease and Mortality in Sub-Saharan Africa. Edited by: Jamison D, Feachem FG, Makgoba MW, Bos ER, Baingana FK, Hofman KJ, Rogo KO. Washington D.C.: World Bank; , 2 2006:

7. Walker RW, McLarty DG, Kitange HM, Whiting D, Masuki G, Mtasiwa DM, Machibya H, Unwin N, Alberti KG: Stroke mortality in urban and rural Tanzania. Adult Morbidity and Mortality Project. Lancet 2000, 355(9216):1684-1687.

8. Mensah GA: Epidemiology of stroke and high blood pressure in Africa. Heart 2008, 94(6):697-705.

9. Tollman SM, Kahn K, Sartorius B, Collinson MA, Clark SJ, Garenne ML: Implications of mortality transition for primary health care in rural South Africa: a population-based surveillance study. Lancet 2008, 372(9642):893-901

10. Omran AR: The epidemiologic transition. A theory of the epidemiology of population change. Milbank Mem Fund Q 1971, 49(4):509-538.

11. van der Sande MA, Bailey R, Faal H, Banya WA, Dolin P, Nyan OA, Ceesay SM, Walraven GE, Johnson GJ, McAdam KP: Nationwide prevalence study of hypertension and related non-communicable diseases in The Gambia. Trop Med Int Health 1997, 2(11):1039-1048.

12. Kamadjeu RM, Edwards R, Atanga JS, Kiawi EC, Unwin N, Mbanya JC: Anthropometry measures and prevalence of obesity in the urban adult 
population of Cameroon: an update from the Cameroon Burden of Diabetes Baseline Survey. BMC Public Health 2006, 6:228.

13. Sodjinou R, Agueh V, Fayomi B, Delisle H: Obesity and cardio-metabolic risk factors in urban adults of Benin: relationship with socio-economic status, urbanisation, and lifestyle patterns. BMC Public Health 2008, 8:84.

14. Christensen DL, Eis J, Hansen AW, Larsson MW, Mwaniki DL, Kilonzo B, Tetens I, Boit MK, Kaduka L, Borch-Johnsen K, et al: Obesity and regional fat distribution in Kenyan populations: impact of ethnicity and urbanization. Ann Hum Biol 2008, 35(2):232-249.

15. Kearney PM, Whelton M, Reynolds K, Muntner P, Whelton PK, He J: Global burden of hypertension: analysis of worldwide data. Lancet 2005, 365(9455):217-223.

16. Opie LH, Seedat YK: Hypertension in sub-Saharan African populations. Circulation 2005, 112(23):3562-3568.

17. Addo J, Smeeth L, Leon DA: Hypertension in sub-Saharan Africa: a systematic review. Hypertension 2007, 50(6):1012-1018.

18. Wild S, Roglic G, Green A, Sicree R, King H: Global prevalence of diabetes: estimates for the year 2000 and projections for 2030. Diabetes Care 2004, 27(5):1047-1053

19. Mbewu A, Mbanya JC: Cardiovascular Diseases. In Disease and Mortality in Sub-Saharan Africa. Edited by: Jamison D, Feachem FG, Makgoba MW, Bos ER, Baingana FK, Hofman KJ, Rogo KO. Washington D.C.: World Bank; , 2 2006:

20. World Urbanization Prospects: The 2007 Revision Population Dataset. [http://esa.un.org/unup/].

21. Poulter NR, Khaw KT, Hopwood BE, Mugambi M, Peart WS, Rose G, Sever PS: The Kenyan Luo migration study: observations on the initiation of a rise in blood pressure. Bmj 1990, 300(6730):967-972.

22. Unwin N, James P, McLarty D, Machybia H, Nkulila P, Tamin B, Nguluma M, McNally R: Rural to urban migration and changes in cardiovascular risk factors in Tanzania: a prospective cohort study. BMC Public Health 2010, $10: 272$.

23. Brown IJ, Tzoulaki I, Candeias V, Elliott P: Salt intakes around the world: implications for public health. Int J Epidemiol 2009, 38(3):791-813.

24. Colin Bell A, Adair LS, Popkin BM: Ethnic differences in the association between body mass index and hypertension. Am J Epidemiol 2002, 155(4):346-353.

25. Agyemang C, Bhopal R: Is the blood pressure of people from African origin adults in the UK higher or lower than that in European origin white people? A review of cross-sectional data. J Hum Hypertens 2003, 17(8):523-534

26. Brown MJ: Hypertension and ethnic group. Bmj 2006, 332(7545):833-836.

27. Yusuf S, Hawken S, Ounpuu S, Dans T, Avezum A, Lanas F, McQueen M, Budaj A, Pais $P$, Varigos J, et al: Effect of potentially modifiable risk factors associated with myocardial infarction in 52 countries (the INTERHEART study): case-control study. Lancet 2004, 364(9438):937-952.

28. Steyn K, Sliwa K, Hawken S, Commerford P, Onen C, Damasceno A, Ounpuu S, Yusuf S: Risk factors associated with myocardial infarction in Africa: the INTERHEART Africa study. Circulation 2005, 112(23):3554-3561.

29. Milne FJ, Veriava Y, James SH, Isaacson C: Aetiology and pathogenesis of malignant hypertension in black South Africans-a review. S Afr Med J 1989, Suppl:22-23.

30. James WP: The epidemiology of obesity: the size of the problem. J Intern Med 2008, 263(4):336-352.

31. Turner AG, Magnani RJ, Shuaib M: A not quite as quick but much cleaner alternative to the Expanded Programme on Immunization (EPI) Cluster Survey design. Int J Epidemiol 1996, 25(1):198-203.

32. Accutrend ${ }^{\oplus}$ GC Detailed information. 2010 [http://www.diavant.com/ diavant/CMSFront.html?pgid=3\%2C1\%2C4\%2C1\#catalog.data].

33. Chobanian AV, Bakris GL, Black HR, Cushman WC, Green LA, Izzo JL Jr, Jones DW, Materson BJ, Oparil S, Wright JT Jr, et al: Seventh report of the Joint National Committee on Prevention, Detection, Evaluation, and Treatment of High Blood Pressure. Hypertension 2003, 42(6):1206-1252.

34. World Health Organization: Diabetes Mellitus. Report of a WHO Study Group Technical Report Series 727. Geneva: World Health Organization 1985.

35. Executive Summary of The Third Report of The National Cholesterol Education Program (NCEP) Expert Panel on Detection, Evaluation, And Treatment of High Blood Cholesterol In Adults (Adult Treatment Panel III). Jama 2001, 285(19):2486-2497.
36. World Health Organization: Obesity: preventing and managing the global epidemic. Report of a WHO Consultation. WHO Technical Report Series 894. Geneva: World Health Organization 2000.

37. Kuper H, Polack S, Eusebio C, Mathenge W, Wadud Z, Foster A: A casecontrol study to assess the relationship between poverty and visual impairment from cataract in Kenya, the Philippines, and Bangladesh. PLoS Med 2008, 5(12):e244.

38. Ebrahim S, Montaner D, Lawlor DA: Clustering of risk factors and social class in childhood and adulthood in British women's heart and health study: cross sectional analysis. Bmj 2004, 328(7444):861.

39. Aspray TJ, Mugusi F, Rashid S, Whiting D, Edwards R, Alberti KG, Unwin NC: Rural and urban differences in diabetes prevalence in Tanzania: the role of obesity, physical inactivity and urban living. Trans R Soc Trop Med Hyg 2000, 94(6):637-644.

40. Cappuccio FP, Micah FB, Emmett L, Kerry SM, Antwi S, Martin-Peprah R, Phillips RO, Plange-Rhule J, Eastwood JB: Prevalence, detection, management, and control of hypertension in Ashanti, West Africa. Hypertension 2004, 43(5):1017-1022.

41. Connor MD, Thorogood M, Casserly B, Dobson C, Warlow CP: Prevalence of stroke survivors in rural South Africa: results from the Southern Africa Stroke Prevention Initiative (SASPI) Agincourt field site. Stroke 2004, 35(3):627-632.

42. Cooper R, Rotimi C, Ataman S, McGee D, Osotimehin B, Kadiri S, Muna W, Kingue $S$, Fraser $H$, Forrester $T$, et al: The prevalence of hypertension in seven populations of west African origin. Am J Public Health 1997, 87(2):160-168.

43. Kerry SM, Emmett L, Micah FB, Martin-Peprah R, Antwi S, Phillips RO, Plange-Rhule J, Eastwood JB, Cappuccio FP: Rural and semi-urban differences in salt intake, and its dietary sources, in Ashanti, West Africa. Ethn Dis 2005, 15(1):33-39.

44. Unwin N, Setel P, Rashid S, Mugusi F, Mbanya JC, Kitange H, Hayes L, Edwards R, Aspray T, Alberti KG: Noncommunicable diseases in subSaharan Africa: where do they feature in the health research agenda? Bull World Health Organ 2001, 79(10):947-953.

\section{Pre-publication history}

The pre-publication history for this paper can be accessed here: http://www.biomedcentral.com/1471-2458/10/569/prepub

\section{doi:10.1186/1471-2458-10-569}

Cite this article as: Mathenge et al:: Urbanization, ethnicity and cardiovascular risk in a population in transition in Nakuru, Kenya: a population-based survey. BMC Public Health 2010 10:569.

\section{Submit your next manuscript to BioMed Central and take full advantage of:}

- Convenient online submission

- Thorough peer review

- No space constraints or color figure charges

- Immediate publication on acceptance

- Inclusion in PubMed, CAS, Scopus and Google Scholar

- Research which is freely available for redistribution

Submit your manuscript at www.biomedcentral.com/submit
C Biomed Central 